BNL-111768-2016-JA

\title{
Anion Solvation in Carbonate-Based Electrolytes
}

\author{
Arthur von Wald Cresce, ${ }^{*},^{\dagger}$ Mallory Gobet, ${ }^{\ddagger}$ Oleg Borodin, ${ }^{\dagger}$ Jing Peng, ${ }^{\ddagger} \S$ Selena M. Russell, ${ }^{\dagger}$ \\ Emily Wikner, ${ }^{\dagger}$ Adele Fu, ${ }^{\dagger}$ Libo Hu, ${ }^{\prime}$ Hung-Sui Lee, ${ }^{\perp}$ Zhengcheng Zhang, ${ }^{\|}$Xiao-Qing Yang, ${ }^{\perp}$ \\ Steven Greenbaum, ${ }^{\ddagger}$ Khalil Amine, ${ }^{\|}$and Kang $\mathrm{Xu}^{\dagger}$ \\ ${ }^{\dagger}$ Electrochemistry Branch, Sensors and Electron Devices, U.S. Army Research Laboratory, Adelphi, Maryland 20783, United States \\ ${ }^{\ddagger}$ Department of Physics and Astronomy and ${ }^{\S}$ Chemistry Doctorate Program, City University of New York, New York, New York \\ 10065, United States \\ "Chemical Sciences and Engineering Division, Argonne National Laboratory, Argonne, Illinois 60439, United States \\ ${ }^{\perp}$ Chemistry Department, Brookhaven National Laboratory, Long Island, New York 11973, United States
}

\section{Supporting Information}

ABSTRACT: With the correlation between $\mathrm{Li}^{+}$solvation and interphasial chemistry on anodes firmly established in Li-ion batteries, the effect of cation-solvent interaction has gone beyond bulk thermodynamic and transport properties and become an essential element that determines the reversibility of electrochemistry and kinetics of Li-ion intercalation chemistries. As of now, most studies are dedicated to the solvation of $\mathrm{Li}^{+}$, and the solvation of anions in carbonate-based electrolytes and its possible effect on the electrochemical stability of such electrolytes remains little understood. As a mirror effort to prior $\mathrm{Li}^{+}$solvation studies, this work focuses on the interactions between carbonate-based solvents and two anions (hexafluorophosphate, $\mathrm{PF}_{6}^{-}$, and tetrafluoroborate, $\mathrm{BF}_{4}^{-}$) that are most frequently used in Li-ion batteries. The possible correlation between such interaction and the interphasial chemistry on cathode surface is also explored.

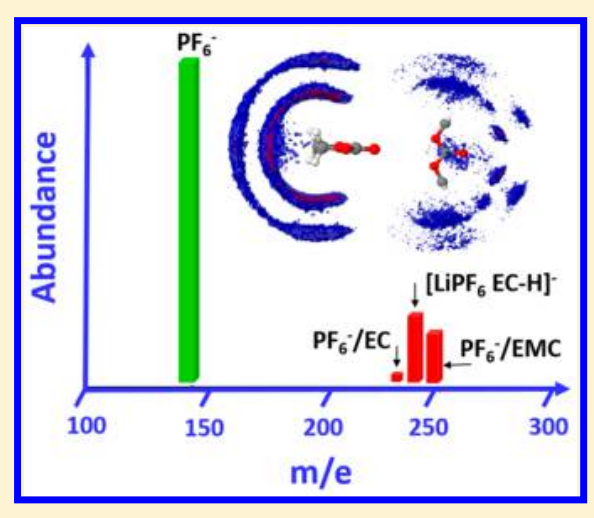

\section{INTRODUCTION}

Li-ion intercalation chemistries are supported by the ad hoc formation of interphases on electrode surfaces. ${ }^{1}$ Such interphases are solid electrolytes in nature, i.e., electronically insulating to prevent sustained electrolyte decomposition but ionically conductive to allow $\mathrm{Li}^{+}$-migration required by cell reactions. The existence of such interphases has been proven beyond doubt on graphitic anodes that operate at potentials far below the thermodynamic stability limit of any nonaqueous electrolyte components $\left(0.2 \mathrm{~V}\right.$ vs $\mathrm{Li} / \mathrm{Li}^{+}$or $-3.0 \mathrm{~V}$ vs standard hydrogen electrode, or SHE). On cathode surfaces, the existence of an interphase still incurs occasional controversy and seems to be highly dependent on the operating potentials and surface state of the cathode itself. For example, an interphase may never form on a $\mathrm{LiFePO}_{4}$-based cathode $(3.5 \mathrm{~V}$ vs $\mathrm{Li} / \mathrm{Li}^{+}$or $0.5 \mathrm{~V}$ vs $\left.\mathrm{SHE}\right)$, but there is no doubt that electrolytes become unstable on either $\mathrm{LiNi}_{0.5} \mathrm{Mn}_{1.5} \mathrm{O}_{4}$ or $\mathrm{LiCoPO}_{4}\left(>4.5 \mathrm{~V}\right.$ vs $\mathrm{Li} / \mathrm{Li}^{+}$or $>1.5 \mathrm{~V}$ vs $\left.\mathrm{SHE}\right)$, resulting in surface deposits that could function as SEI. ${ }^{2}$

Given its importance, the interphase on graphitic anodes has been thoroughly investigated in the past two decades, from its key ingredients identification ${ }^{3}$ and formation mechanism ${ }^{4}$ to the more recent revelation on how the $\mathrm{Li}^{+}$-solvation sheath relates to the interphasial chemistry during the prereduction stage of cointercalation ${ }^{5}$ and the transport process through it thereafter. ${ }^{6,7}$ On the other hand, because of its conditional existence, little attention has been paid to cathode interphase until rather recently, when high-voltage cathodes of $>4.5 \mathrm{~V}$ came into consideration. Initial studies indicated a preference for EC vs DMC and enrichment of anion at the cathode surface. ${ }^{8}$ Thus, anions could play an active role in solvent oxidation $^{9}$ or prevention of Al corrosion. A logical question thus extended is whether solvation of anions by electrolyte solvent affects passivation processes on the cathode surface. To seek an answer, the present work investigates how anion and solvent molecules interact in typical carbonate-based electrolytes. Attempts are also made to reveal the existence or absence of preferential solvation and whether a correlation that mirrors $\mathrm{Li}^{+}$solvation and anode interphasial chemistry exists for cathode interphases. Such fundamental understanding would be crucial to the efforts in designing electrolyte components and interphases that support high-voltage chemistries in Li-ion batteries.

\section{EXPERIMENTAL SECTION}

Lithium hexafluorophosphate $\left(\mathrm{LiPF}_{6}\right)$ and lithium tetrafluoroborate $\left(\mathrm{LiBF}_{4}\right)$ were purchased from Morita Chemical Industries and Ferro, respectively. They were stored in an argon-filled glovebox (Vacuum Atmospheres Nexus One, <1 ppm of $\mathrm{O}_{2},<1$ ppm of $\left.\mathrm{H}_{2} \mathrm{O}\right)$ and used as received. Ethylene 
carbonate (EC), ethylmethyl carbonate (EMC), and dimethyl carbonate (DMC) were purchased from BASF and dried over 3 $\AA$ molecular sieves that have been preactivated at $400{ }^{\circ} \mathrm{C}$, followed by storage in the argon glovebox until needed. Anion receptor tris(pentafluorophenyl)borane (TPFPB) was synthesized at Brookhaven National Lab and purified by sublimation in the dryroom at the Army Research Lab before use. All electrolytes were prepared in the glovebox to minimize moisture inclusion.

Electrospray ionization mass spectrometry (ESI-MS) data were collected by a JEOL AccuTOF mass spectrometer operating in negative mode for anionic cluster detection. The sample injection chamber was filled with dry nitrogen and heated to $250{ }^{\circ} \mathrm{C}$, with a needle-plate potential of $1000 \mathrm{~V}$. Data were analyzed using JEOL mass spectrometry software, with peak height data culled from mass spectrometry spectrum intensity at expected anion-solvent $\mathrm{m} / \mathrm{z}$ ranges. Nuclear magnetic resonance (NMR) experiments were performed with a 400 SB Bruker Avance III spectrometer $(9.4 \mathrm{~T})$. To avoid any interaction between the electrolyte and the NMR tube (borosilicate glass), the samples were placed in a $4 \mathrm{~mm}$ Teflon tube and inserted in a $5 \mathrm{~mm}$ NMR tube containing a chemical shift reference of deuterated solvent (setup depicted in the Supporting Information). This setup allowed both optimal chemical shift referencing and optimal adjustment of magnetic field homogeneity (i.e., shimming) using ${ }^{2} \mathrm{H}$ lock signal for each sample. $\mathrm{CFCl}_{3}$ in $\mathrm{CDCl}_{3}$ and boric acid in $\mathrm{D}_{2} \mathrm{O}$ were used as external reference solutions (set to $0 \mathrm{ppm}$ ) for ${ }^{2} \mathrm{~F}$ and ${ }^{11} \mathrm{~B}$ experiments, respectively. Self-diffusion coefficients for ${ }^{1} \mathrm{H},{ }^{19} \mathrm{~F}$, and ${ }^{7} \mathrm{Li}$ nuclei were measured at $25{ }^{\circ} \mathrm{C}$ using a double stimulated echo pulse sequence to suppress convection effects. ${ }^{10}$ Gradient strength was arrayed (32 values, linear increase, $g=0-45 \mathrm{G} / \mathrm{cm}$ ) for each experiment. Gradient pulse duration was $\delta=1.5-4 \mathrm{~ms}$, and diffusion delay was $\Delta=150-$ $400 \mathrm{~ms}$.

Molecular dynamics (MD) simulations were performed on the $\mathrm{LiPF}_{6} / \mathrm{EC} / \mathrm{DMC}(1: 1 \mathrm{~mol} \%)$ and $\mathrm{LiBF}_{4} / \mathrm{EC}: \mathrm{DMC}(1: 1$ mol \%) electrolytes in order to examine anion-solvent interactions. A modified APPLE\&P many-body polarizable force field for $\mathrm{EC} / \mathrm{Li}^{+}$and $\mathrm{DMC} / \mathrm{Li}^{+}$was used in conjunction with the previously reported $\mathrm{LiPF}_{6}$ and $\mathrm{LiBF}_{4}$ force fields. ${ }^{11}$ The functional form of APPLE\&P force field is described elsewhere. ${ }^{12}$ Briefly, it utilizes atomic charges centered on atoms and off-atom positions in conjunction with the atomcentered isotropic dipole polarizability to represent Coulomb and polarization interactions. The induced dipoles are smeared with the Thole screening parameter $\left(a_{\mathrm{T}}=0.4\right)$ in order to prevent the so-called "polarization catastrophe" from occurring. The repulsion-dispersion interactions were described using a Buckingham (also called exp-6) potential. The interaction between an induced dipole and a partial charge was excluded for all atoms in EC, $\mathrm{DMC}, \mathrm{PF}_{6}{ }^{-}$, and $\mathrm{BF}_{4}{ }^{-}$with the exception of interaction between $-\mathrm{CH}_{3}$ groups in DMC. The 1-2 and 1-3 force centers were excluded from the charge-charge and repulsion-dispersion interactions. Partial charges for EC and DMC were refitted to reproduce the electrostatic potential from quantum chemistry calculations at the Møller-Plesset perturbation theory (MP2/aug-cc-pvTz) in the slab around the solvents, following a previously described methodology. ${ }^{12}$ The solvent $/ \mathrm{Li}^{+}$repulsion parameters were fitted to describe the $\mathrm{EC} / \mathrm{Li}^{+}$and $\mathrm{DMC} / \mathrm{Li}^{+}$binding energy for 562 and 550 positions of $\mathrm{Li}^{+}$around EC and DMC, respectively. The binding energy was calculated using M06-L functional and 6$31+\mathrm{G}(\mathrm{d}, \mathrm{p})$ basis set.

A modified MD simulation package WMI-MD was used that includes many-body polarization. Each simulation cell contained $320 \mathrm{EC}, 320 \mathrm{DMC}$ molecules, and $64 \mathrm{LiPF}_{6}$ for EC:DMC (1:1 mol \%)/LiPF 6 and $480 \mathrm{EC}, 352 \mathrm{DMC}$, and 64 $\mathrm{LiBF}_{4}$ for EC:DMC(1:1 vol \%) doped with $1 \mathrm{M} \mathrm{LiBF}_{4}$. Electrolytes were equilibrated at $393 \mathrm{~K}$ for $4 \mathrm{~ns}$, followed by NPT equilibration runs at $333 \mathrm{~K}$ for 2-9 ns. The EC:DMC/ $\mathrm{LiBF}_{4}$ was further equilibrated for $20 \mathrm{~ns}$ at room temperature in NPT ensemble followed by 25 ns production run in NVT ensemble. The Ewald summation method was used for the electrostatic interactions between permanent charges with induced dipole moments with $k=6^{3}$ vectors. Multiple time step integration was employed with an inner time step of $0.5 \mathrm{fs}$ (bonded interactions), a central time step of $1.5 \mathrm{fs}$ for all nonbonded interactions within a truncation distance of 7.0-8.0 $\AA$, and an outer time step of 3.0 fs for all nonbonded interactions between $7.0 \AA$ and the nonbonded truncation distance of $14 \AA$. The reciprocal part of Ewald was updated only at the largest of the multiple time steps. A Nosé-Hoover thermostat and a barostat were used to control the temperature and pressure with the associated frequencies of $10^{-2}$ and $0.1 \times$ $10^{-4} \mathrm{fs}$.

\section{RESULTS AND DISCUSSION}

Since Li-ion battery chemistry is driven by the insertion and removal of $\mathrm{Li}^{+}$in electrode lattice structures, the movement and solvation of $\mathrm{Li}^{+}$have been naturally considered key properties. The counterions, however, were often treated as invisible other than offering global electroneutrality. Their interaction with solvent and possible participation in interphasial chemistry often went unnoticed, until unexpected chemistries caused by anion reactions became impossible to ignore. Examples include superconcentrated electrolytes, in which the scarcity of solvent molecules at high concentrations of $\mathrm{Li}$ salts forced anions to appear more frequently in the $\mathrm{Li}^{+}$-solvation sheath and led to interphasial chemistries that are otherwise improbable in relatively dilute $(\sim 1.0 \mathrm{M})$ electrolyte solutions. ${ }^{13-16}$ In fact, even in these conventional electrolytes for Li-ion batteries, an anion, though not directly participating intercalation reactions, must satisfy a series of requirements to support the cell reactions. Such requirements include low nucleophilicity or weak association with the cation (so that decent solubility and dissociation degree can be achieved in nonaqueous solvents), sufficient chemical and electrochemical inertness against electrodes, current collectors, and other cell components and, on occasion, being able to form a protective interphase on all of them. ${ }^{17}$ The short list of anions simultaneously meeting the above rigorous standards include hexafluorophosphate $\left(\mathrm{PF}_{6}{ }^{-}\right)$, hexafluoroarsenate $\left(\mathrm{AsF}_{6}{ }^{-}\right)$, tetrafluoroborate $\left(\mathrm{BF}_{4}^{-}\right)$, and perhaps perchlorate $\left(\mathrm{ClO}_{4}^{-}\right)$. Among these, $\mathrm{PF}_{6}{ }^{-}$became the current industry standard that can be found in almost all commercial Li-ion batteries because its lithium salt meets all these requirements in the most balanced manner, ${ }^{18,19}$ with $\mathrm{LiBF}_{4}$ used only for niche applications. Other exotic anions, such as imides (as represented by bis(trifluoromethanesulfonyl)imide, $\left.\mathrm{TFSI}^{-}\right)$or bis(oxalato)borate $\left(\mathrm{BOB}^{-}\right)$, though providing certain unique advantages over $\mathrm{PF}_{6}^{-}$, failed to balance these requirements and hence were confined to laboratory research applications. In this work we selected both $\mathrm{PF}_{6}{ }^{-}$and $\mathrm{BF}_{4}{ }^{-}$as candidates to investigate. Despite their extensive 

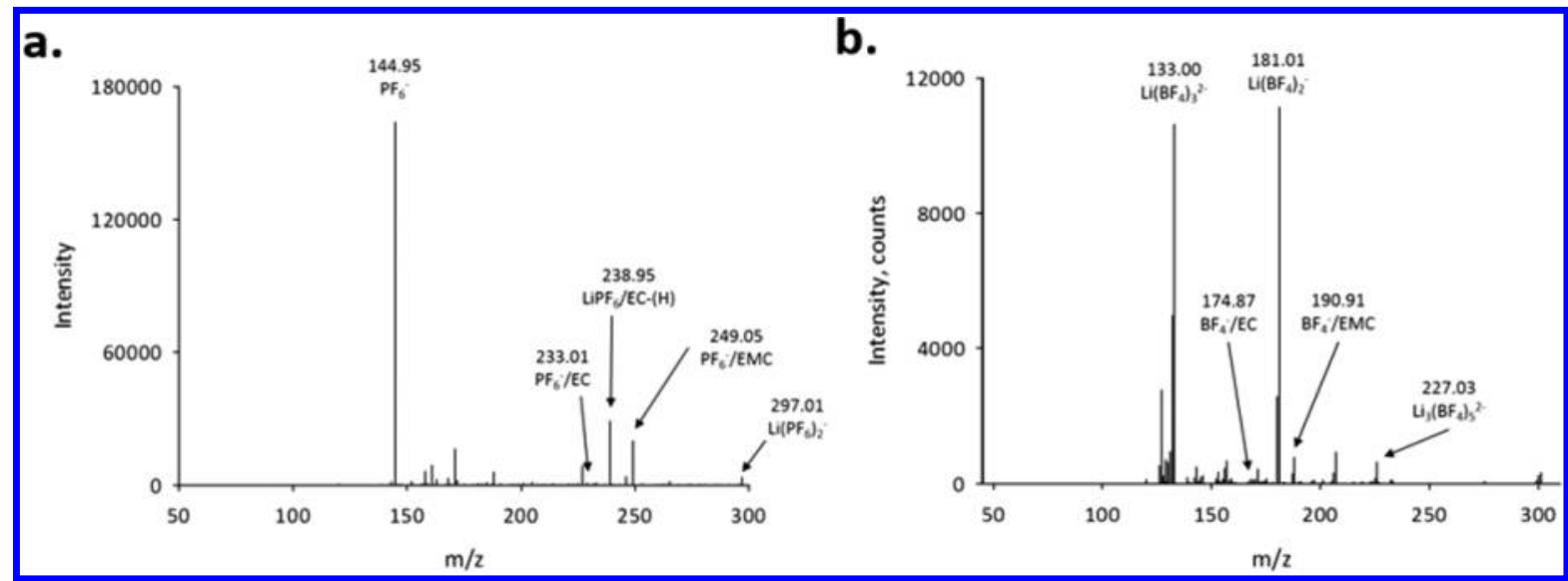

Figure 1. Typical mass spectra via electrospray ionization for (a) $1.0 \mathrm{M} \mathrm{LiPF}_{6}$ in EC/EMC (50:50) and (b) $1.0 \mathrm{M} \mathrm{LiBF}_{4}$ in $\mathrm{EC}_{\mathrm{EMC}}(30: 70)$.

applications, little is known about their interactions with solvents with the exception of a few recent publications. ${ }^{20,21}$

Electrospray-Ionization Mass Spectra. In previous work, electrospray-ionization mass spectrometry (ESI-MS) was innovatively used in conjunction with ${ }^{17} \mathrm{O}$ NMR and molecular dynamics as a powerful tool to map the $\mathrm{Li}^{+}$-solvation sheath structure both qualitatively and quantitatively. The combination of these techniques unambiguously revealed preferential solvation of $\mathrm{Li}^{+}$and identified the solvent molecules most tightly coordinated. ${ }^{5 b, 19,22}$ When the negative mode of this technique was applied to electrolytes based on $\mathrm{PF}_{6}{ }^{-}$and $\mathrm{BF}_{4}{ }^{-}$ anions in the full range of EC/EMC ratios, a striking difference was immediately noticed as compared to positive mode $\left(\mathrm{Li}^{+}-\right.$ solvent) spectra: the anion-solvent species detected were only present at low percentages $(<1 \%)$ of the overall signal abundances. Figures $1 \mathrm{a}$ and $1 \mathrm{~b}$ show the typical spectra collected from EC/EMC 50:50 and 30:70 solutions with $1 \mathrm{M}$ $\mathrm{LiPF}_{6}$ and $1 \mathrm{M} \mathrm{LiBF}_{4}$, respectively. Spectra of all other solutions are shown in Figures S1 and S2.

This scarce presence of anion-solvent species agrees, in principle, with the knowledge that association of anion to solvent molecules is much weaker as compared with that between $\mathrm{Li}^{+}$and solvent, ${ }^{21,23}$ as evidenced by the often higher transference number of anion than cation despite the smaller ionic radii of the cation. ${ }^{18}$ Of particular interest is the spectrum of $\mathrm{LiPF}_{6}$ solution, where the most conspicuous species is the free anion itself $\left(\mathrm{PF}_{6}^{-}\right)$as given by $\mathrm{m} / z 144.9$ in Figure la. Considering that naked cation was never detected in any ESIMS spectra, ${ }^{5 b, 24}$ the presence of a free $\mathrm{PF}_{6}^{-}$alludes to an extremely weak anion-solvent interaction. Meanwhile, the minor presence of cation-anion species, as represented by $\left[\mathrm{Li}\left(\mathrm{PF}_{6}\right)_{2}\right]^{-}$at $m / z$ 297.01, indicates how well $\mathrm{LiPF}_{6}$ is dissociated in the carbonate mixture at the concentrations investigated $(\sim 1.0 \mathrm{M})$. The weak association properties of $\mathrm{PF}_{6}{ }^{-}$ result from the combined effects of highly electronegative fluorine attached to a polarizable phosphorus center, which consequently makes $\mathrm{HPF}_{6}$ a superacid and hence confers on any salt based on such anions a low dissociation energy barrier. The peak at $m / z 238.95$ (with the second highest abundance in Figure 1a) seems to represent a decomposed species consisting of $\mathrm{LiPF}_{6}$ adduct with a $[\mathrm{EC}-\mathrm{H}]^{-}$anion. This peak appears with varying abundances in all $\mathrm{LiPF}_{6}$-based electrolytes with the exception in neat EMC solution and does not seem to depend on EC/EMC ratio. Its formation might undergo a transition state or intermediate involving the complexation between $\mathrm{PF}_{6}^{-}$ and EC, followed by the defluorination of $\mathrm{PF}_{6}{ }^{-}$and deprotonation of $\mathrm{EC}$ by the strong Lewis acid $\mathrm{PF}_{6}{ }^{-}$. A possible mechanism is proposed in Scheme 1. The starting species can

Scheme 1. Proposed EC-PF 6 Complex Leading to Deprotonation of EC That Could Account for the ESI-MS Peak at $m / z 238.95$ Corresponding to the Complex $\mathrm{LiPF}_{6}{ }^{\circ}$ $[\mathrm{EC}-\mathrm{H}]^{-}$

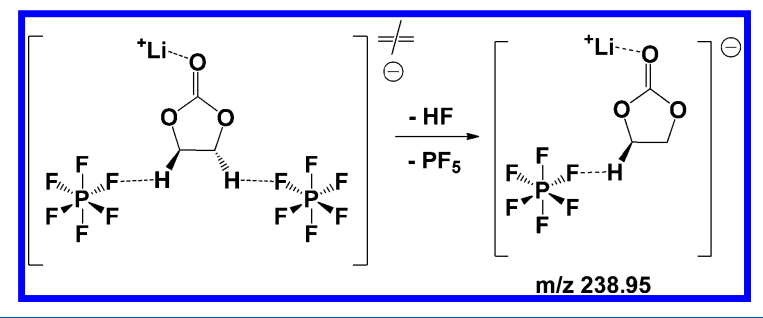

be viewed as a supermolecular complex formed among $\mathrm{Li}^{+}$, $\mathrm{PF}_{6}{ }^{-}$, and an EC molecule, in which the interaction between $\mathrm{Li}^{+}$ and $\mathrm{EC}$ activates the $\mathrm{H}$ atoms on $\mathrm{EC}$ to form a hydrogen bond with F.

Interestingly, neither $\left[\mathrm{LiPF}_{6} \cdot \mathrm{DMC}-\mathrm{H}\right]^{-}$nor $\left[\mathrm{LiPF}_{6} \cdot \mathrm{EMC}\right.$ $\mathrm{H}]^{-}$was found. Their absence might be related to the preference of $\mathrm{EC}$ by $\mathrm{PF}_{6}^{-}$over acyclic carbonate molecules such as DMC and EMC, which is in accord with the higher binding energy of $18.4 \mathrm{kcal} / \mathrm{mol}$ for $\mathrm{EC} / \mathrm{PF}_{6}{ }^{-}$compared to binding energy of $7.0 \mathrm{kcal} / \mathrm{mol}$ for $\mathrm{DMC}(\mathrm{cis}-\mathrm{cis}) / \mathrm{PF}_{6}{ }^{-}$ obtained from LC- $\omega$ PBE/6-31+G(d) DFT calculations with Grimme empirical dispersion included. More recently, using Raman, fluorescence, and NMR, Schroder et al. also concluded that $\mathrm{H}$-bonding exists between $\mathrm{PF}_{6}{ }^{-}$and hydrogen in carbonate molecules, which is structurally similar to the starting intermediate species in the proposed mechanism. ${ }^{25}$ In this sense, the intermediate in Scheme 1 not only constitutes the precursor for such deprotonation/defluorination reactions but also, more importantly, represents how anion and solvent species might exist with each other in the bulk electrolyte solution. Very likely, only under electrospraying conditions will such an intermediate become unstable and consequently break down, which might be catalyzed by the high temperature during injection $\left(250^{\circ} \mathrm{C}\right)$.

A quite different story resulted from ESI-MS of $\mathrm{LiBF}_{4}$-based solutions. Although there is similarly little presence of anionsolvent interaction as indicated by the low abundance of $\left[\mathrm{BF}_{4}\right.$ $\mathrm{EC}]^{-}$at $m / z 174.87$ and $\left[\mathrm{BF}_{4} \mathrm{EMC}\right]^{-}$at $m / z 190.91$, the naked 
$\mathrm{BF}_{4}^{-}(m / z$ 87) never appeared (Figure $1 \mathrm{~b}$ and Figure $\mathrm{S} 1)$. Instead, varying $\mathrm{Li}_{x}^{+}\left(\mathrm{BF}_{4}^{-}\right)_{y}$ aggregates dominate the spectra, as indicated by $\left[\mathrm{Li}\left(\mathrm{BF}_{4}\right)_{3}\right]^{2-}$ at $m / z$ 133.00, $\left[\mathrm{Li}\left(\mathrm{BF}_{4}\right)_{2}\right]^{-}$at $m / z$ 181.01, and $\left[\mathrm{Li}_{3}\left(\mathrm{BF}_{4}\right)_{5}\right]^{2-}$ at $m / z$ 227.03. This is consistent with the established knowledge that $\mathrm{LiBF}_{4}$ dissociates to a lesser degree than does $\mathrm{LiPF}_{6}{ }^{11 b, 26}$ as $\mathrm{HBF}_{4}$ is a much weaker superacid than $\mathrm{HPF}_{6}{ }^{18,27}$ Upon closer examination, $\mathrm{m} / z$ 181.01 could arise from two isobaric species, $\left[\mathrm{Li}\left(\mathrm{BF}_{4}\right)_{2}\right]^{-}$and $\left[\mathrm{LiBF}_{4}(\mathrm{EC}-\mathrm{H})\right]^{-}$, the latter of which could be produced in a mechanism similar to Scheme 1 . This coincidence, caused by the almost identical molecular weights of $\mathrm{BF}_{4}^{-}$and $(\mathrm{EC}-\mathrm{H})^{-}$, makes it difficult to quantitatively deconvolute the relative distributions of EC and EMC in close proximity to $\mathrm{BF}_{4}{ }^{-}$.

A quantitative analysis was conducted on ESI-MS spectra for both solutions in an attempt to identify whether preferential solvation exists for anions as it does for $\mathrm{Li}^{+}$. As pointed out in our previous $\mathrm{Li}^{+}$-solvation work, this information is critically important to commercial Li-ion batteries, where the electrolytes are almost always based on mixtures of solvents instead of single solvents, and any preferential solvation might lead to drastically different interphasial chemical compositions as well as electrochemical behavior. The population of EC molecules as found in the anion-solvent species is thus plotted against the electrolyte bulk composition for electrolytes containing both $\mathrm{PF}_{6}^{-}$and $\mathrm{BF}_{4}^{-}$anions (Figure 2). For $\mathrm{PF}_{6}^{-}$solutions we

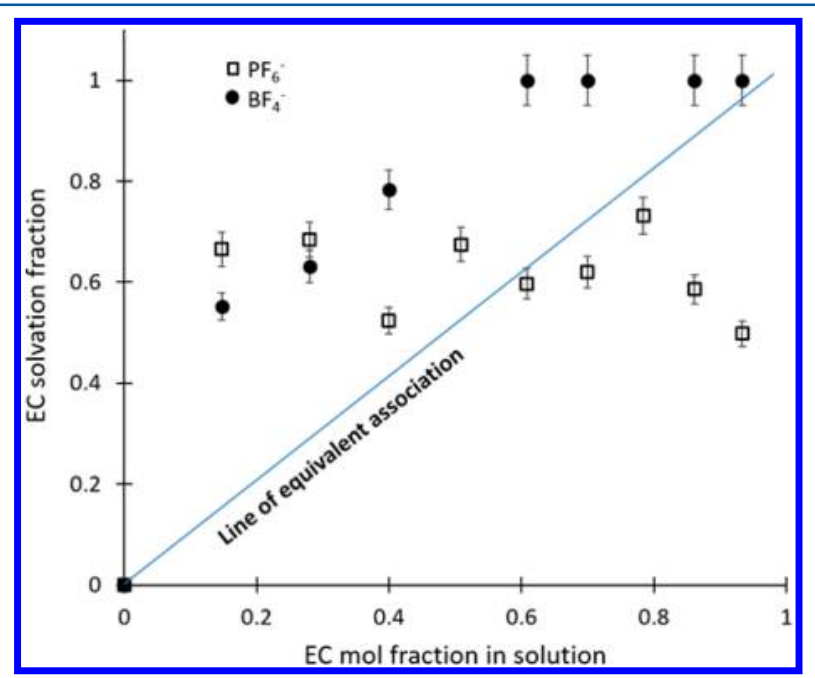

Figure 2. Comparison of EC populations as found in coordination complexes with $\mathrm{PF}_{6}^{-}$and $\mathrm{BF}_{4}^{-}$.

considered the population of decomposed species $\left[\mathrm{LiPF}_{6}(\mathrm{EC}-\right.$ $\mathrm{H})]^{-}$as a reflection of the population of $\left[\mathrm{PF}_{6} \mathrm{EC}\right]^{-}$aggregates, based on the Raman interpretation by Schroder et al.; ${ }^{25}$ for $\mathrm{BF}_{4}{ }^{-}$solutions, however, since it is impossible to distinguish the abundance of $\left[\mathrm{BF}_{4} \mathrm{EC}\right]^{-}$aggregates at $\mathrm{m} / z$ 181.01, we simply excluded it from the calculation. It should be kept in mind that the contribution of EC population could be significantly underestimated in such analysis. In all electrolytes investigated here EC is found to be preferentially bonded with both anions, although the bias is not as significant when compared with the preferential solvation of $\mathrm{Li}^{+}$. We attribute this difference to the much weaker anion-solvent interactions. It has been hypothesized that the anions $\mathrm{PF}_{6}{ }^{-}$and $\mathrm{BF}_{4}{ }^{-}$would also exhibit preferential solvation in mixed cyclic/linear carbonate electrolytes as $\mathrm{Li}^{+}$does. For example, Ong et al. proposed that anions should prefer cyclic over linear carbonates through computa- tion because the molecular configuration of the former is more polar due to the ring constraint. ${ }^{28}$ The efforts to detect such a tendency accurately and quantitatively using ESI-MS, however, is challenged by the weak association between anion and solvent and the transient disintegration of such clusters during the flight stage of the electrospraying process.

NMR Characterization. Nuclear magnetic resonance (NMR) was also applied to the electrolytes containing both anions. Considering that these anions are highly fluorinated, ${ }^{19} \mathrm{~F}$ NMR spectra were collected for these electrolytes at varying ratios of EC/DMC. Here DMC replaces EMC in all NMR experiments, and the difference incurred by this replacement is expected to be negligible in both bulk and interphasial properties $^{1 b, 18}$ due to the structural similarity of the two acyclic carbonates. Figure 3 summarizes the change in ${ }^{19} \mathrm{~F}$ chemical

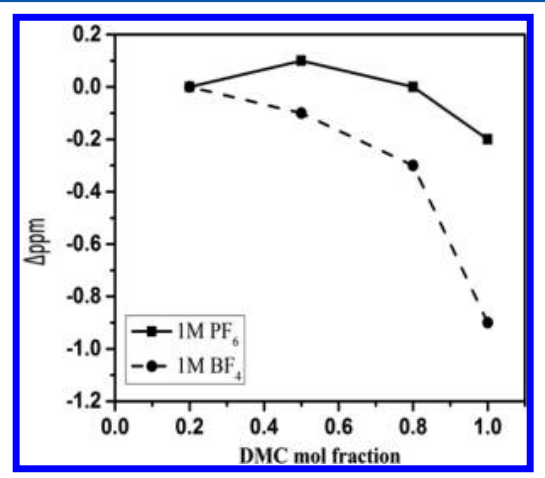

Figure 3. Normalized ${ }^{19} \mathrm{~F}$ chemical shifts of solutions of $\mathrm{LiPF}_{6}$ and $\mathrm{LiBF}_{4}$ referenced to the shift value at EC/DMC 80:20 for both salts.

shift $(\Delta \delta)$ as the ratio of binary electrolytes varies, where $\Delta \delta$ was normalized as against the ${ }^{19} \mathrm{~F}$ signals at DMC mole fraction of 0.2. The ${ }^{19} \mathrm{~F}$ chemical shift of both anions exhibit an upfield shift as the solution dielectric constant decreases (i.e., with increasing DMC content), leading to a progressive shielding effect of ${ }^{19} \mathrm{~F}$ nuclei. The upfield shift of ${ }^{19} \mathrm{~F}$ of $\mathrm{LiBF}_{4}$ with increasing of DMC content is a solvent effect similar to that observed by the work of Plakhotnyk et al., ${ }^{29}$ which confirmed that the ${ }^{19} \mathrm{~F}$ chemical shift of $\mathrm{BF}_{4}^{-}$in various solvents moves upfield as the solution dielectric constant decreases. The $\mathrm{PF}_{6}^{-}$ anion was expected to follow the same trend of this upfield shift, as observed in this work. The $\mathrm{LiPF}_{6}$ salt in a spread of EC/DMC electrolytes showed a very small ${ }^{19} \mathrm{~F}$ chemical shift range of less than $0.3 \mathrm{ppm}$ over all tested electrolytes. A lack of ${ }^{19} \mathrm{~F}$ chemical shift variation implies the composition of the solvents does not significantly change the surrounding environment of $\mathrm{PF}_{6}^{-}$anions and in particular that the anion remains well separated from the $\mathrm{Li}^{+}$despite the decreasing permittivity of the solution. However, $\mathrm{LiBF}_{4}$ displayed a significantly larger chemical shift range of about $0.9 \mathrm{ppm}$ with the various amounts of DMC. This difference is attributed to the greater tendency of $\mathrm{LiBF}_{4}$ to form ion pairs or higher aggregates, which is exacerbated by decreasing solvent polarity. The diffusion behavior of all species, either ions or solvent molecules, is largely dominated by the solution viscosity, which in turn is mostly determined by EC/DMC ratio. In order to eliminate the effect of viscosity as a variable, $\mathrm{PF}_{6}{ }^{-}, \mathrm{BF}_{4}{ }^{-}$, and $\mathrm{Li}^{+}$mobilities are expressed as the ratio between their respective diffusion coefficients and that of DMC. The ratios are presented in Figure $4 . \mathrm{Li}^{+}$shows a rather constant ratio around 0.4 in $\mathrm{LiPF}_{6}$ systems, which is lower than that of the 


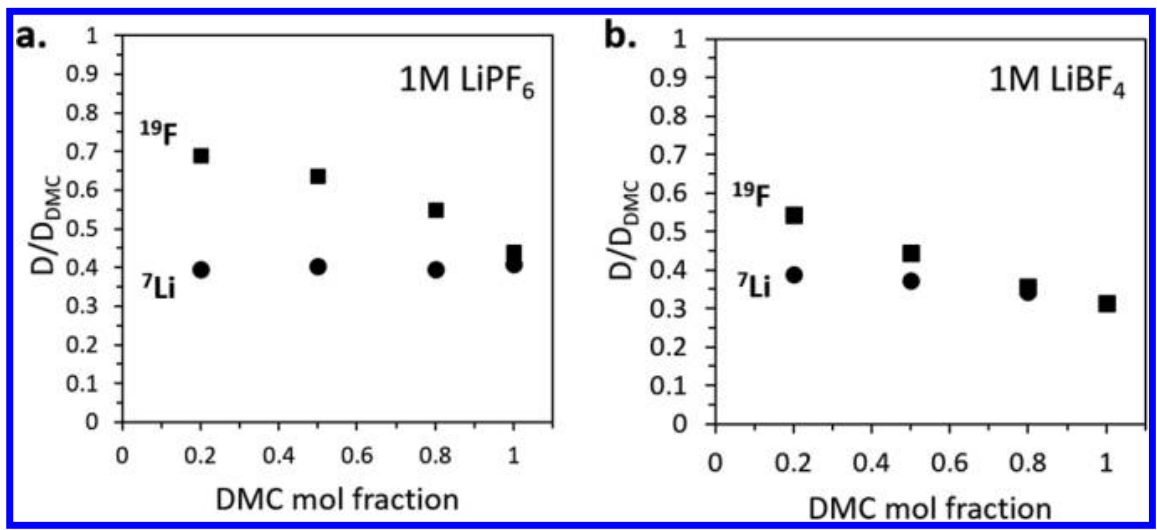

Figure 4. Relative mobilities of $\mathrm{Li}$ and $\mathrm{F}$ in (a) $1 \mathrm{M} \mathrm{LiPF}_{6}$ and (b) $1 \mathrm{M} \mathrm{LiBF}_{4}$ solutions.

Scheme 2. (a) Anion Receptor Tris(pentafluorophenyl)borane (TPFPB) and (b) Interaction of Anions $\mathrm{PF}_{6}{ }^{-}$and $\mathrm{BF}_{4}{ }^{-}$with TPFPB Resulting in Fluorination of TPFPB and Creation of Neutral Species $\mathrm{PF}_{5}$ and $\mathrm{BF}_{3}$, Respectively

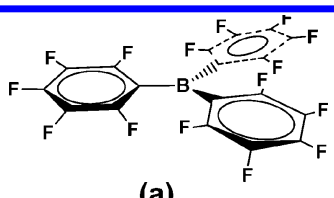

(a)

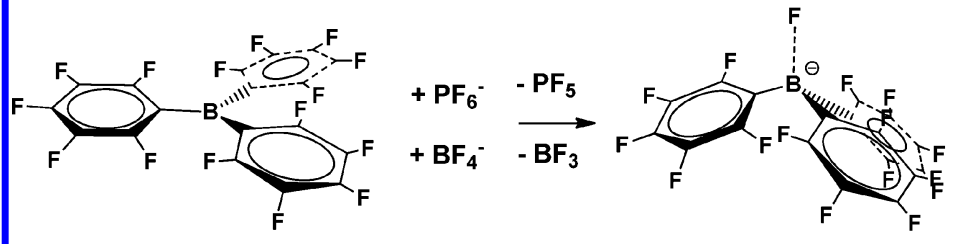

(b)

m/e 530
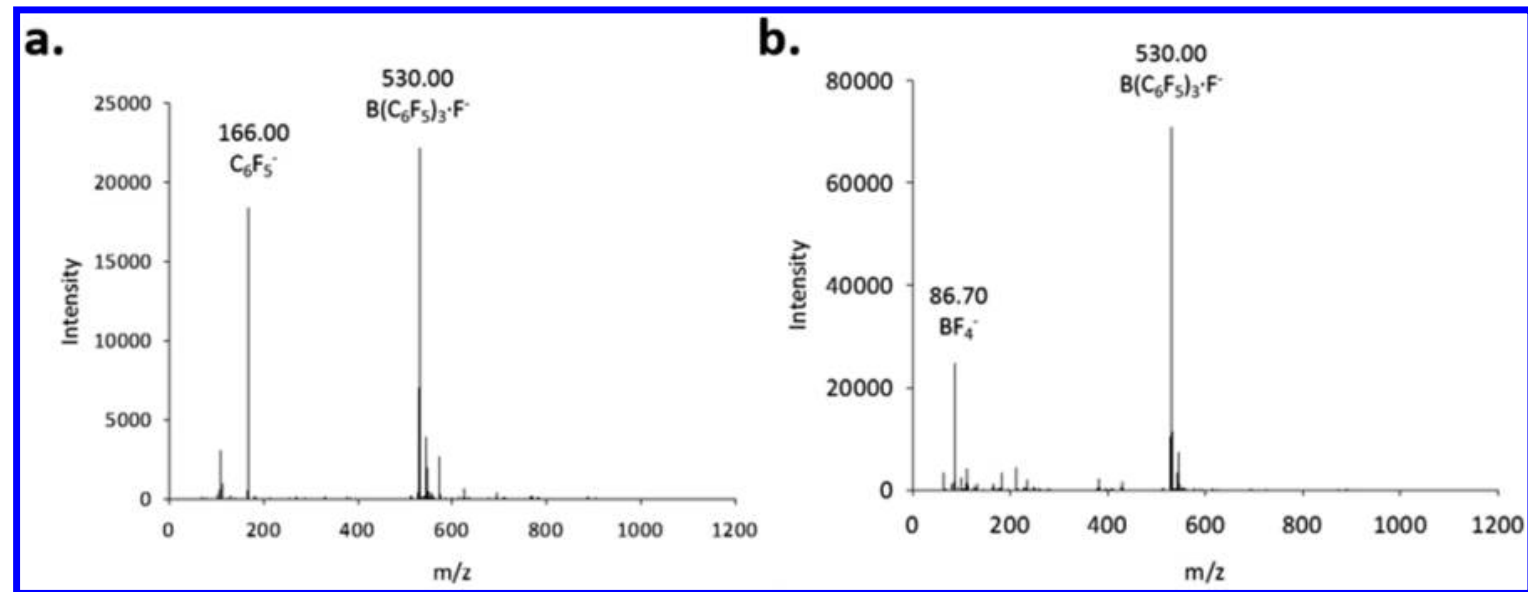

Figure 5. Effect of anion receptor TPFPB on the anion-solvent interaction: (a) $\mathrm{LiPF}_{6}$ and (b) $\mathrm{LiBF}_{4}$ in EC/DMC (50:50).

anion. This is due to the solvation sheath of $\mathrm{Li}^{+}$being saturated by solvent molecules, $\mathrm{EC}$ in particular. In both $\mathrm{LiPF}_{6}$ and $\mathrm{LiBF}_{4}$, the relative mobility of fluorine is higher for low DMC content (i.e., high polarity), and it progressively converges toward the $\mathrm{Li}^{+}$ratio as the polarity of the system decreases. This feature indicates that the decrease in solvent polarity favors association of cation and anion, as the less polar solvent molecules are much less effective in neutralizing the electric field exerted by ionic species (mainly $\mathrm{Li}^{+}$) on its surroundings. This weaker presence of anion-solvent interaction predicts that solvent molecules in such low-polarity media will be less likely to be found in the vicinity of both cation and anion. It is noteworthy that the difference between the mobility of $\mathrm{Li}^{+}$and $\mathrm{BF}_{4}^{-}$is much smaller than in the $\mathrm{LiPF}_{6}$ system, and $\mathrm{BF}_{4}{ }^{-}$has almost identical mobility as $\mathrm{Li}^{+}$in EC/DMC 20/80 solution or higher DMC contents. This phenomenon again arises from the stronger ion association tendency of $\mathrm{LiBF}_{4}$ compared to $\mathrm{LiPF}_{6}$. Because of the interference from cation-anion interaction, at this time it is difficult to ascertain the specific preference of anion solvation via NMR methods.

Anion-Receptor Effect. So far we have been avoiding the term "anion-solvation sheath", mainly because the weak interaction between the two leads to doubt whether a stable sheath structure could actually exist long enough. As pointed 


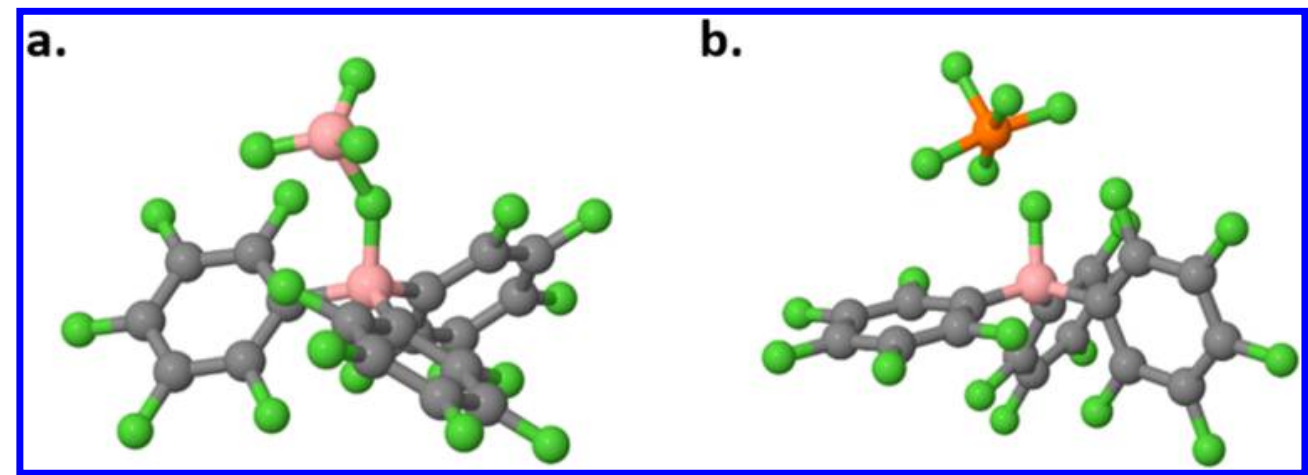

Figure 6. Optimized geometries of TPFPB complexes with (a) $\mathrm{BF}_{4}^{-}$and (b) $\mathrm{PF}_{6}^{-}$anions from LC- $\omega$ PBE-GD3/6-31+G(d) DFT calculations.
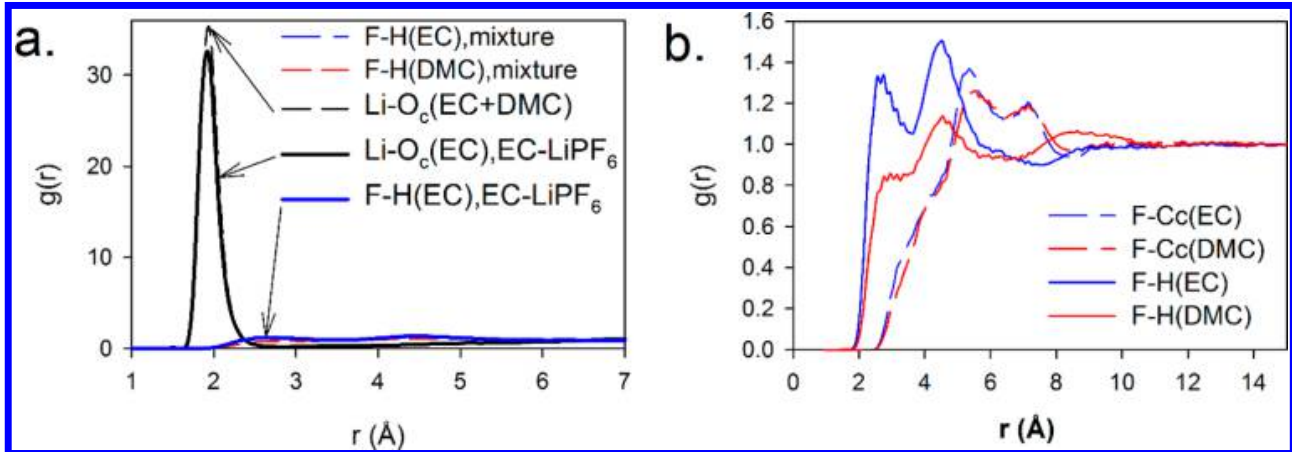

Figure 7. Molecular dynamics simulation of the radial distribution function of $\mathrm{LiPF}_{6}$ in EC and EC:DMC. (a) $\mathrm{Li}^{+}$and $\mathrm{PF}_{6}^{-} / \mathrm{F}^{-}$to solvent $\mathrm{H}_{\text {and }}$ carbonyl oxygen $\left(\mathrm{O}_{\mathrm{c}}\right)$, including $\mathrm{F}-\mathrm{H}$ of $\mathrm{EC}$ and $\mathrm{EC}: \mathrm{EMC}, \mathrm{Li}-\mathrm{O}_{\mathrm{c}}$ in EC:EMC, and $\mathrm{F}-\mathrm{O}_{\mathrm{c}}$ in EC. Compared to the structured, close binding of $\mathrm{Li}^{+}$ to carbonyl oxygens, the distribution of anion $\mathrm{F}$ to solvent $\mathrm{H}(\mathrm{F}-\mathrm{H})$ peaks after $2 \AA$ indicates much less structuring of anions. Comparing the $\mathrm{F}-\mathrm{H}$ (solid line) distributions in Figure $6 \mathrm{~b}$ predicts greater $\mathrm{PF}_{6}{ }^{-}$interaction with $\mathrm{EC}$ compared to DMC.

out by Chaban et al., with such loose attraction between anion and solvent, even the primary solvation sheath of anions would be difficult to define. ${ }^{21}$ The origin for the diffused structure of anion solvation can be attributed to the fact that the majority of polar aprotic solvents are nucleophilic in nature, and the dissolution of solutes relies mostly on the coordination of electropositive substructure in the solute by these nucleophiles. Thus, in Li-ion battery electrolytes, the point-charge $\mathrm{Li}^{+}$forms strong bonds with the lone-pair electrons in carbonyl moieties on carbonate, as revealed by both ESI-MS and ${ }^{17} \mathrm{O}$ NMR, while the absence of a strong electrophilic substructure in carbonate or ether solvents leads to insignificant solvation of anions.

In order to achieve the ideal situation of an unambiguous anion-solvent association, we introduced an anion receptor into the electrolytes, so that the intrinsic absence of anionbinding sites in the latter could be overcome. The structure of tris(pentafluorophenyl)borane (TPFPB, Scheme 2a) was designed to provide an electron-deficient boron center, and previous investigations have confirmed its efficiency in solvating various anions, including the anion for one of the least soluble lithium salts, $\mathrm{LiF}^{30}$

Upon addition of only $0.1 \mathrm{~mol} \%$ TPFPB, dramatic changes occurred in the ESI-MS for both $\mathrm{LiPF}_{6}$ and $\mathrm{LiBF}_{4}$-based electrolytes, resulting in much cleaner spectra (Figure 5) and distinct new species. However, in neither case was the expected simple adduct between TPFPB and anion detected, as indicated by the absence of species at $m / z 654\left[\mathrm{TPFPB}+\mathrm{PF}_{6}{ }^{-}\right]$and 596 $\left[\mathrm{TPFPB}+\mathrm{BF}_{4}^{-}\right]$, respectively. Instead, the overwhelmingly abundant species found in both electrolytes is [TPFPB $+\mathrm{F}^{-}$] $(\mathrm{m} / z$ 530.88), arising from the defluorination of these two anions by the anion receptor (Scheme $2 b$ ). The lability of P-
$\mathrm{F} / \mathrm{B}-\mathrm{F}$ bonds together with the strong affinity of TPFPB toward $\mathrm{F}^{-}$makes such a defluorination process possible. DFT calculations performed using LC- $\omega$ PBE functional with GD3 empirical dispersion correction and $6-31+\mathrm{G}(\mathrm{d})$ basis set indicated that the $\mathrm{BF}_{4}^{-}$and $\mathrm{PF}_{6}^{-}$interaction with TPFPB resulted in the spontaneous defluorination of anions with reaction free energies of -24.4 and $-12.7 \mathrm{kcal} / \mathrm{mol}$ for TPFPB $+\mathrm{BF}_{4}{ }^{-}$and $\mathrm{TPFPB}+\mathrm{PF}_{6}{ }^{-}$complex formation, respectively. As a result of anion complexation by TPFPB, the $\mathrm{B}-\mathrm{F}$ bond in $\mathrm{BF}_{4}{ }^{-}$extends but less than the $\mathrm{P}-\mathrm{F}$ bond in $\mathrm{PF}_{6}^{-}$. In other words, fluorine is shared between $\mathrm{BF}_{4}^{-}$and TPFPB, while it is largely transferred to the anion receptor in the TPFPB- $-\mathrm{PF}_{6}^{-}$ complex as shown in Figure 6. As fluorine is shared between TPFPB and $\mathrm{BF}_{4}{ }^{-}$in the complex, it could form either F-TPFPB complex or $\mathrm{BF}_{4}^{-}$in ESI-MS experiments as shown in Figure 5. The free energy for $\mathrm{PF}_{5}$ and $\mathrm{BF}_{3}$ dissociation from the $\mathrm{FPB}+$ $\mathrm{PF}_{6}$ and $\mathrm{FPB}+\mathrm{BF}_{4}$ complexes was 0.2 and $2.0 \mathrm{kcal} / \mathrm{mol}$, respectively, indicating that both $\mathrm{BF}_{3}$ and especially $\mathrm{PF}_{5}$ could easily detach. Since both species are neutral in charge, ESI-MS is blind to them.

Suspicion has been raised previously regarding the stability of $\mathrm{LiPF}_{6}$ or $\mathrm{LiBF}_{4}$ against strong anion receptors like TPFPB; ${ }^{31,32}$ observations made in Figure 5 confirmed experimentally for the first time that a strong anion receptor does have the tendency of breaking down these highly fluorinated inorganic anions. The removal of fluorine incurs the question whether anion receptors are unsuitable for the electrolytes containing these anions because the strong Lewis acids generated from the process $\left(\mathrm{PF}_{5}\right.$ and $\left.\mathrm{BF}_{3}\right)$ will very likely trigger a series of electrophilic reactions with the organic carbonate molecules, 
leading to extensive electrolyte degradation. ${ }^{33}$ A conclusive answer to this question requires further studies.

The most interesting, but somewhat unexpected, effect of the anion receptor is that naked $\mathrm{BF}_{4}{ }^{-}$anion could be detected now as an abundant species (Figure $5 b$ ), which was never observed in the ESI-MS of the electrolytes without TPFPB (Figure 1b) because of poorly dissociated $\mathrm{LiBF}_{4}$. Thus, it is reasonable to assume that in the bulk electrolytes the dissociation of $\mathrm{LiBF}_{4}$ was indeed promoted by the anion receptor. We postulate that the adduct $\left[\mathrm{TPFPB}+\mathrm{BF}_{4}^{-}\right]$formed in the electrolyte very likely experienced fragmentation during the electrospraying stage, losing the neutral TPFPB and leading to naked $\mathrm{BF}_{4}{ }^{-}$. We can even further infer that both $\left[\mathrm{TPFPB}+\mathrm{PF}_{6}{ }^{-}\right]$and $[\mathrm{TPFPB}$ $\left.+\mathrm{BF}_{4}^{-}\right]$were formed in the electrolytes and served as precursor of fragmentation to produce the abundant species [TPFPB + $\left.\mathrm{F}^{-}\right]$in both cases. The more labile $\mathrm{P}-\mathrm{F}$ bond drives the fragmentation process to generate overwhelmingly [TPFPB + $\mathrm{F}^{-}$, while the more stable $\mathrm{B}-\mathrm{F}$ bond manages to maintain an equilibrium between the two different fragmentation routes, producing both $\left[\mathrm{TPFPB}+\mathrm{F}^{-}\right]$and $\left[\mathrm{BF}_{4}^{-}\right]$, consistent with computational analysis.

Molecular Dynamic Simulations. To aid understanding of anion-solvent interaction, we employed computational simulations so that a mechanism at the atomic level could be derived. MD simulations were performed on EC:DMC (1:1 vol $\%)$ doped $1 \mathrm{M} \mathrm{LiBF}_{4}$ (solvent:Li = 13) and EC:DMC(1:1 mol $\%$ ) doped $\mathrm{LiPF}_{6}$ (at solvent:Li $=10$ ), with the purpose of examining how anion binds to either EC or DMC. Figure 7 compares radial distribution functions (RDFs) for both $\mathrm{Li}^{+}$with carbonyl oxygen $\left(\mathrm{Li}-\mathrm{O}_{\mathrm{c}}\right)$ and $\mathrm{F}$ with hydrogen $(\mathrm{F}-\mathrm{H})$. They serve as indicators for the solvent structuring around cation and anion. Consistent with previous studies, a highly structured solvation environment exists for $\mathrm{Li}^{+}$as evidenced by the high amplitude of the sharp first peak of $\mathrm{Li}-\mathrm{O}_{\mathrm{c}} \mathrm{RDF}$. A similar strong peak was observed for $\mathrm{F}$ in $\mathrm{PF}_{6}$ and carbonyl oxygen $\mathrm{O}_{c}$. However, the almost featureless $\mathrm{RDF}$ for $\mathrm{F}$ in $\mathrm{PF}_{6}$ and $\mathrm{H}$ suggest much less structuring of solvent molecules around anions. A more detailed comparison of anion coordination in the single and mixed solvents is made in Figure $7 \mathrm{~b}$, where the $\mathrm{F}-\mathrm{H}$ RDFs indicate a much stronger association between $\mathrm{H}$ from $\mathrm{EC}$ with $\mathrm{PF}_{6}{ }^{-}$than $\mathrm{H}$ from $\mathrm{DMC}$ with $\mathrm{PF}_{6}^{-}$, hinting at preferential interaction of anion with EC rather than DMC. This preference is in agreement with the slightly lower binding energy between $\mathrm{EC}$ and $\mathrm{PF}_{6}{ }^{-}$than $\mathrm{DMC}$ and $\mathrm{PF}_{6}^{-}$(Table 1).

Table 1. G4MP2 Calculation of Anion-Solvent Binding and Free Energy

\begin{tabular}{lcc} 
& binding energy $(\mathrm{kcal} / \mathrm{mol})$ & free energy $(\mathrm{kcal} / \mathrm{mol})$ \\
$\mathrm{PF}_{6}{ }^{-}-\mathrm{EC}$ & -16.7 & -7.5 \\
$\mathrm{PF}_{6}{ }^{-}-\mathrm{DMC}$ & -7.1 & 1.4 \\
$\mathrm{BF}_{4}{ }^{-}-\mathrm{EC}$ & -18.0 & -8.9 \\
$\mathrm{BF}_{4}{ }^{-}-\mathrm{DMC}$ & -7.1 & 1.2 \\
\hline
\end{tabular}

Interestingly, almost identical RDFs were obtained for the $\mathrm{F}-$ $\mathrm{C}_{\mathrm{c}}$ (carbonyl carbon) for both EC and DMC. As $\mathrm{C}_{\mathrm{c}}$ is near the location of the solvent center of mass, it might indicate that from the point of view of the solvent center of mass both solvents have similar structuring with anions.

In a more visual representation, the distributions of $\mathrm{F}$ from $\mathrm{PF}_{6}{ }^{-}$in the vicinity of both $\mathrm{EC}$ and DMC molecules are calculated and shown in Figure 8. It shows two isosurfaces corresponding to $\rho / \rho_{\text {bulk }}=5$ (in red) and $\rho / \rho_{\text {bulk }}=3$ (in blue) for EC-anion and $\rho / \rho_{\text {bulk }}=3$ (in red) and $\rho / \rho_{\text {bulk }}=2.3$ (in blue) for DMC-anion, where $\rho$ is the local density of atom and $\rho_{\text {bulk }}$ is the average density of atom in the whole simulation box. The red isosurface indicates the most probable position of $\mathrm{F}$ of anion, while the blue isosurface indicates a slightly less probably positions but still preferred compared to average number density. For DMC with its weaker dipole (Figure $8 \mathrm{a}$ ), $\mathrm{PF}_{6}{ }^{-}$is most probable near its methyl group as well as its carbonyl carbon. In comparison, EC presents a much cleaner picture of $\mathrm{PF}_{6}{ }^{-}$location probability near the positive end of the EC dipole, which is the methylene end (Figure $8 \mathrm{~b}$ ). As shown by Schroder et al., $\mathrm{F}$ in anions prefers to coordinate with olefin Hs in EC and DMC and likely form hydrogen bond, and we believe that the supermolecular structure as shown in Figure $8 \mathrm{~b}$ probably mediates the subsequent dehydrogenation of EC by $\mathrm{PF}_{6}{ }^{-}$, leading to the species $\left[\mathrm{LiPF}_{6}{ }^{-}(\mathrm{EC}-\mathrm{H})\right]$ at $m / z 238.95$ (Figure 1a).

The distribution of anions and $\mathrm{Li}^{+}$around solvent molecules in the EC:DMC/LiBF 4 electrolyte is shown in Figure 9. It shows two isosurfaces: one corresponding to high probability of finding fluorine of $\mathrm{BF}_{4}^{-} \rho / \rho_{\text {bulk }}=4$ (in red in Figures $9 \mathrm{a}, \mathrm{c}$ ) and $\mathrm{Li}^{+} \rho / \rho_{\text {bulk }}=33$ (in blue). The other two (Figures $9 \mathrm{~b}, \mathrm{~d}$ ) show the intermediate probability of finding fluorine of $\mathrm{BF}_{4}^{-} \rho / \rho_{\text {bulk }}$ $=2$ (in red) and $\mathrm{Li}^{+} \rho / \rho_{\text {bulk }}=33$ (in blue). While there are substantial similarities between the locations of $\mathrm{PF}_{6}^{-}$(see Figure $8 \mathrm{~b}$ ) and $\mathrm{BF}_{4}^{-}$(Figure 9a) near the ethylene part of $\mathrm{EC}$, there are also noticeable differences. Specifically, some $\mathrm{BF}_{4}{ }^{-}$ anions are located near carbonyl oxygens due to their coordination to the $\mathrm{Li}^{+}$cations and higher $\mathrm{LiBF}_{4}$ salt aggregation compared to $\mathrm{LiPF}_{6}$. In contrast to the $\mathrm{EC}-\mathrm{BF}_{4}{ }^{-}$ most probable coordination via $\mathrm{EC}$ ethylene group, the most probable position of the $\mathrm{BF}_{4}{ }^{-}$anions is near the $\mathrm{DMC}$ carbonyl carbons, indicating that the $\mathrm{DMC} / \mathrm{BF}_{4}{ }^{-}$interactions are largely modulated by the $\mathrm{DMC} / \mathrm{Li}^{+}$and $\mathrm{Li}^{+} / \mathrm{BF}_{4}{ }^{-}$interactions. Interestingly, there is a substantial similarity between the solvent-lithium-anion packing found in our simulations in liquid electrolytes and the solvate structures obtained from crystal structures. $^{34}$ Higher probability of the direct $\mathrm{H} \cdots \mathrm{F}$ interaction in $\mathrm{EC} / \mathrm{PF}_{6}^{-}$compared to solvent/ $\mathrm{BF}_{4}^{-}$would indicate that at high potentials $\left(>6 \mathrm{~V}\right.$ vs $\left.\mathrm{Li} / \mathrm{Li}^{+}\right)$kinetics of $\mathrm{EC} /$ $\mathrm{DMC} / \mathrm{LiPF}_{6}$ oxidation might be higher than kinetics of $\mathrm{EC} /$ $\mathrm{DMC} / \mathrm{LiBF}_{4}$ oxidation due to $\mathrm{H}$-abstraction by anion during oxidation that requires formation of the $\mathrm{H} \cdots \mathrm{F}$ contracts. ${ }^{9}$

Implication to Electrochemistry. Considering the weak association, it will be safe to speculate that the solvation of anions imposes little influence on the overall anodic stability of the electrolytes, regardless if they exhibit preferential solvation or not. Note that this is not to state that anion has no effect on anodic stability; instead, what dictates the anodic stability limit should be the chemical and electrochemical stability of the anions and the solvent molecules altogether. To confirm this experimentally, EC/EMC-based electrolytes with both lithium salts are exposed to a $\mathrm{LiFePO}_{4}$ cathodes surface that is progressively delithiated, where $\mathrm{LiFePO}_{4}$ serves as a working electrode with redox peaks $(\sim 3.5 \mathrm{~V}$ vs $\mathrm{Li})$ far below the decomposition region $(>4.0 \mathrm{~V})$ of electrolyte components. Using such composite working electrode, instead of more commonly used nonporous electrodes such as glassy carbon or platinum, ${ }^{35}$ ensures more accurate evaluation of the decomposition onset potentials for electrolytes on active electrode surfaces that they will be exposed to in real-life Li-ion devices. ${ }^{36}$ It is generally accepted that the anodic stability of the $\mathrm{PF}_{6}{ }^{-}$and its passivation of current collector (aluminum foil) outperform 


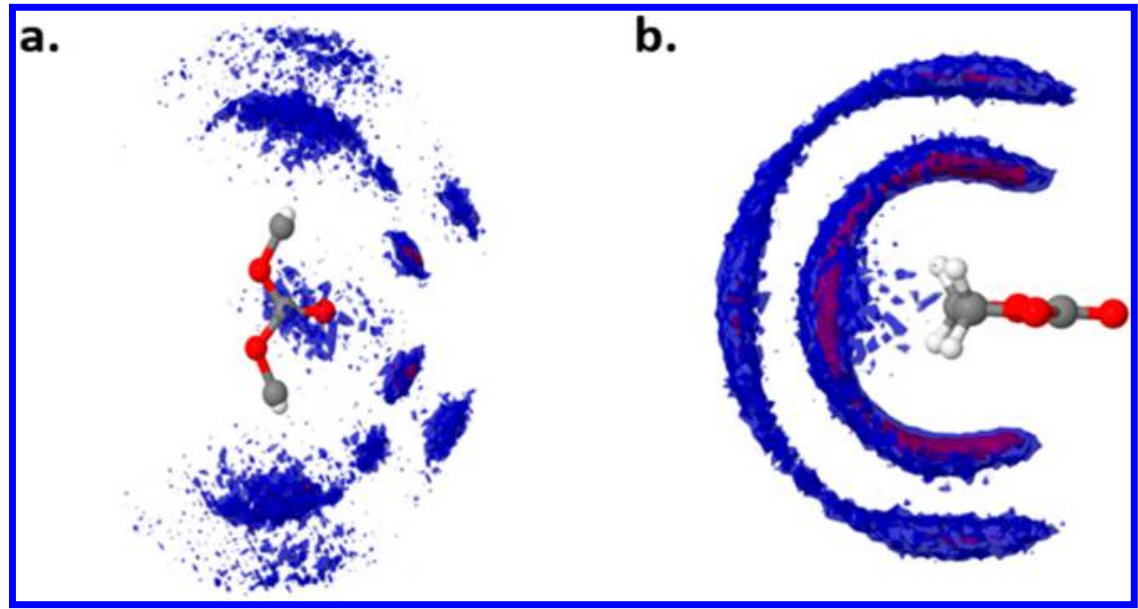

Figure 8. 3D isosurface rendering of $\mathrm{F}$ in $\mathrm{PF}_{6}{ }^{-}$around (a) DMC and (b) EC, with most probable locations marked in red and less probable locations in blue.

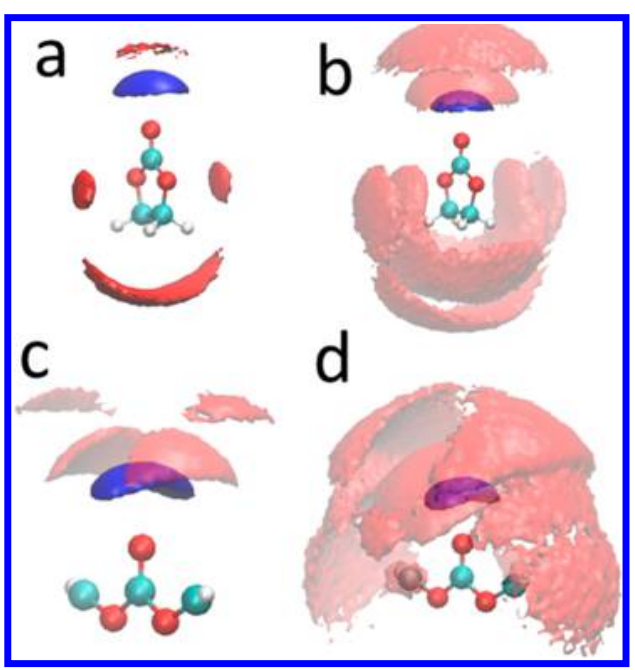

Figure 9. 3D isosurface rendering for high $(a, c)$ and intermediate $(b$, d) probability of fluorine of $\mathrm{BF}_{4}{ }^{-}$around $\mathrm{EC}(\mathrm{a}, \mathrm{c})$ and $\mathrm{DMC}(\mathrm{c}, \mathrm{d})$ (shown as red isosurfaces) in $\mathrm{EC}: \operatorname{DMC}(1: 1 \mathrm{vol} \%) / \mathrm{LiBF}_{4}$. Blue isosurfaces show high probability of $\mathrm{Li}^{+}$.

those of the $\mathrm{BF}_{4}{ }^{-}$, and Figure 10 confirms this difference; on the other hand, the variation in solvent ratio of electrolytes

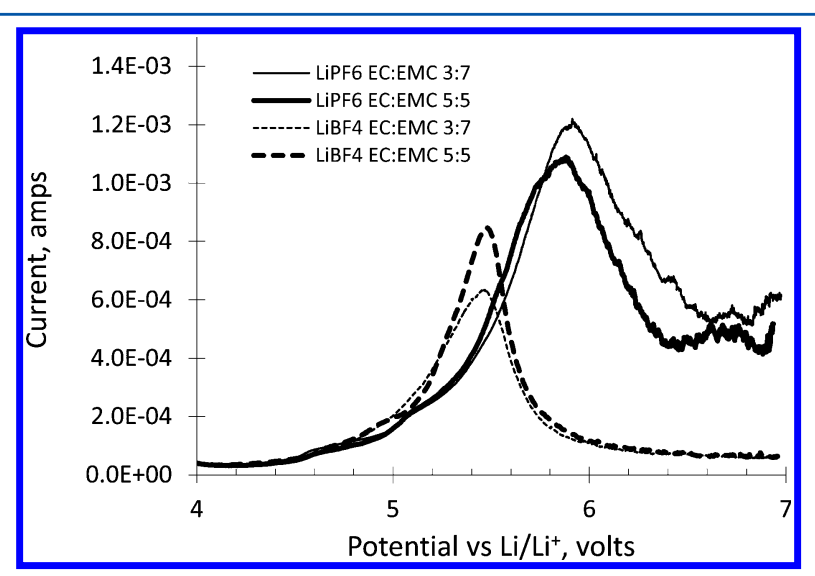

Figure 10. Anodic stability of $\mathrm{PF}_{6}{ }^{-}$-based (solid lines) and $\mathrm{BF}_{4}{ }^{-}$-based (dotted lines) electrolyte as determined by linear sweep technique on a $\mathrm{LiFePO}_{4}$ working electrode. The scan rate for all tested electrolytes was $0.05 \mathrm{mV} / \mathrm{s}$. exhibits little, if any, impact on the potential of electrolyte decomposition. The onset of significant current flow in Figure 10 occurs at about $4.5 \mathrm{~V}$ for both anions, but this is caused by anion intercalation into cathode graphite additive. Staging of $\mathrm{BF}_{4}{ }^{-}$is seen at $4.8 \mathrm{~V}$, while staging of $\mathrm{PF}_{6}{ }^{-}$is seen at 4.6 and $5.1 \mathrm{~V}^{37}$ Coincidently, the onset of oxidation for a similar electrolyte EC/DMC(1:1)/ $\mathrm{LiPF}_{6}$ was reported to occur around $4.6 \mathrm{~V}$ on glassy carbon, ${ }^{38}$ indicating that the onset of staging and oxidation happens at a similar potential resulting in a lower Coulombic efficiency for anion intercalation for this electrolyte. The anodic peaks at 5.4 and $5.9 \mathrm{~V}$ are attributed to the solvent $-\mathrm{BF}_{4}^{-}$and solvent $-\mathrm{PF}_{6}^{-}$oxidation and were largely independent of electrolyte composition. Previous DFT calculations ${ }^{39}$ predicted oxidation of the $\mathrm{EC} / \mathrm{PF}_{6}{ }^{-}$and $\mathrm{DMC} /$ $\mathrm{PF}_{6}{ }^{-}$complexes to happen about $0.3 \mathrm{~V}$ higher than oxidation of the $\mathrm{EC} / \mathrm{BF}_{4}{ }^{-}$and $\mathrm{DMC} / \mathrm{BF}_{4}{ }^{-}$complexes, respectively, in good agreement with the difference between the experimentally measured peak positions. The anodic current at the peak was also higher for the $\mathrm{LiPF}_{6}$-doped electrolyte than for the $\mathrm{LiBF}_{4^{-}}$ doped one. It is possible that the $\mathrm{PF}_{6}{ }^{-}$peak has a higher current than $\mathrm{BF}_{4}^{-}$is caused in part by faster oxidation kinetics as suggested by the higher probability of $\mathrm{H} \cdots \mathrm{F}$ interactions in $\mathrm{PF}_{6}{ }^{-}$compared to $\mathrm{BF}_{4}{ }^{-}$.

Ultimately, the near absence of solvent effect on anodic decomposition process, whether it is formation of interphase on cathode surface or passivation of current collector, apparently arises from the weak association between anions and their solvating molecules, which minimizes the effect of the solvent species on the electrochemical behaviors of electrolytes on cathode surfaces. The slight preferential solvation of anions by EC observed in this work is not strong enough to exert pronounced electrochemical significance analogous to the preferential solvation of $\mathrm{Li}^{+}$.

\section{CONCLUSIONS}

Using electrospray-ionization mass spectrometry (ESI-MS), nuclear magnetic resonance (NMR), and computational simulation, we investigated how anions of lithium salts $\left(\mathrm{PF}_{6}^{-}\right.$ and $\mathrm{BF}_{4}^{-}$) interact with carbonate molecules in typical electrolytes. Spectra indicate that these highly fluorinated anions exist relatively free with little solvation. For the small population of anions that are solvated, slight preferential solvation is found for both anions, with cyclic and more polar solvent EC favored over acyclic and less polar linear carbonates. 
While ESI-MS revealed a few possible ways these anion react with either solvent molecule or added anion receptors, NMR indicates that $\mathrm{F}$ in these anions are the species that intensely interact with the weakly electropositive regions in solvent molecules. The weak anion-solvent interaction seems to at least minimize the solvent effect on the electrochemical behavior of electrolytes on cathode surfaces compared to the pronounced effect of the competitive solvation of EC and DMC to $\mathrm{Li}^{+}$on the SEI formation on anode.

\section{ASSOCIATED CONTENT}

\section{S Supporting Information}

The Supporting Information is available free of charge on the ACS Publications website at DOI: 10.1021/acs.jpcc.5b08895.

Section 1: a more detailed description of the NMR procedures used to collect data presented in the Results and Discussion section; Figure S1: the NMR tube with Teflon sample insert for clarity in understanding the NMR experimental setup; Section 2: a presentation of all electrospray ionization mass spectrographs used to develop the solvation population information in Figure 2 and composed of Figure $\mathrm{S} 2 \mathrm{a}-\mathrm{j}$ displaying $\mathrm{LiPF}_{6}$ ESIMS data and Figures S3a-j displaying LiBF4 ESI-MS data; Section 3: composed of Figures S4-S7, providing additional isosurface views of both $\mathrm{Li}^{+}$and $\mathrm{F}^{-}$from from the $\mathrm{BF}_{4}^{-}$anion around both EC and DMC; Figure S8: a closer view of the radial distribution function presented in Figure 10 to more clearly show the magnitude of the $\mathrm{F}-\mathrm{H}$ distribution values compared to the much larger $\mathrm{Li}-\mathrm{O}$ distribution values (PDF)

\section{AUTHOR INFORMATION}

\section{Corresponding Author}

*E-mail arthur.v.cresce.civ@mail.mil (A.v.W.C.).

\section{Notes}

The authors declare no competing financial interest.

\section{ACKNOWLEDGMENTS}

This work is partially funded by US Department of Energy under the Interagency Agreement No. DE-EE0006543. Dr. Selena Russell was supported by an appointment to the US Army Research Laboratory (ARL) Fellowship Program administered by the Oak Ridge Associated Universities through a cooperative agreement with ARL. The authors also thank Yue Li from Department of Chemistry at University of Maryland College Park for his assistance with the mass spectrometry experiments. Ms. Emily Wikner and Ms. Adele Fu were supported by American Society for Engineer Education under summer internship at ARL.

\section{REFERENCES}

(1) (a) Peled, E.; Golodnitsky, D.; Ardel, G. Advanced Model for Solid Electrolyte Interphase Electrodes in Liquid and Polymer Electrolytes. I. Electrochem. Soc. 1997, 144, L208-L210. (b) Xu, K. Electrolytes and Interphases in Li-Ion Batteries and Beyond. Chem. Rev. 2014, 114, 11503.

(2) (a) Sharabi, R.; Markevich, E.; Fridman, K.; Gershinsky, G.; Salitra, G.; Aurbach, D.; Semrau, G.; Schmidt, M. A.; Schall, N.; Bruenig, C. Electrolyte solution for the improved cycling performance of LiCoPO4/C composite cathodes. Electrochem. Commun. 2013, 28, 20-23. (b) von Cresce, A.; Xu, K. Electrolyte Additive in Support of 5 V Li Ion Chemistry. I. Electrochem. Soc. 2011, 158, A337-A342. (c) Borodin, O.; Olguin, M.; Spear, C. E.; Leiter, K. W.; Knap, J.
Towards high throughput screening of electrochemical stability of battery electrolytes. Nanotechnology 2015, 26, 354003.

(3) Aurbach, D.; Zaban, A.; Schechter, A.; Ein-Eli, Y.; Zinigrad, E.; Markovsky, B. The Study of Electrolyte Solutions Based on Ethylene and Diethyl Carbonates for Rechargeable Li Batteries: I. Li Metal Anodes. I. Electrochem. Soc. 1995, 142, 2873-2882.

(4) Winter, M.; Besenhard, J. O.; Spahr, M. E.; Novák, P. Insertion electrode materials for rechargeable lithium batteries. Adv. Mater. 1998, 10, 725-763.

(5) (a) $\mathrm{Xu}, \mathrm{K}$; von Wald Cresce, A. Lit-solvation/desolvation dictates interphasial processes on graphitic anode in $\mathrm{Li}$ ion cells. $\mathrm{I}$. Mater. Res. 2012, 27, 2327-2341. (b) von Cresce, A.; Xu, K. Preferential Solvation of $\mathrm{Li}+$ Directs Formation of Interphase on Graphitic Anode. Electrochem. Solid-State Lett. 2011, 14, A154.

(6) (a) Yamada, Y.; Iriyama, Y.; Abe, T.; Ogumi, Z. Kinetics of Lithium Ion Transfer at the Interface between Graphite and Liquid Electrolytes: Effects of Solvent and Surface Film. Langmuir 2009, 25, 12766-12770. (b) Xu, K.; von Cresce, A.; Lee, U. Differentiating Contributions to "Ion Transfer" Barrier from Interphasial Resistance and $\mathrm{Li}+$ Desolvation at Electrolyte/Graphite Interface. Langmuir 2010, 26, 11538-11543.

(7) Lu, P.; Harris, S. J. Lithium transport within the solid electrolyte interphase. Electrochem. Commun. 2011, 13, 1035-1037.

(8) (a) Vatamanu, J.; Borodin, O.; Smith, G. D. Molecular Dynamics Simulation Studies of the Structure of a Mixed Carbonate/LiPF 6 Electrolyte near Graphite Surface as a Function of Electrode Potential. I. Phvs. Chem. C 2012, 116, 1114-1121. (b) Yu, L.; Liu, H.; Wang, Y.; Kuwata, N.; Osawa, M.; Kawamura, J.; Ye, S. Preferential Adsorption of Solvents on the Cathode Surface of Lithium Ion Batteries. Angew. Chem. 2013, 125, 5865-5868.

(9) (a) Xing, L.; Borodin, O.; Smith, G. D.; Li, W. Density Functional Theory Study of the Role of Anions on the Oxidative Decomposition Reaction of Propylene Carbonate. L.Phvs. Chem. A 2011, 115, 1389613905. (b) Borodin, O. Molecular Modeling of Electrolytes. In Electrolvtes for Lithium and Lithium-Ion Batteries: Jow, T. R., Xu, K., Borodin, O., Ue, M., Eds.; Springer: New York, 2014; Vol. 58, pp 371-401.

(10) Jerschow, A.; Müller, N. Suppression of Convection Artifacts in Stimulated-Echo Diffusion Experiments. Double-Stimulated-Echo Experiments. J. Magn. Reson. 1997, 125, 372-375.

(11) (a) Borodin, O.; Smith, G. D. Quantum Chemistry and Molecular Dynamics Simulation Study of Dimethyl Carbonate: Ethylene Carbonate Electrolytes Doped with LiPF 6 . L.Phys. Chem. B 2009, 113, 1763-1776. (b) Seo, D. M.; Borodin, O.; Han, S.-D.; Boyle, P. D.; Henderson, W. A. Electrolyte Solvation and Ionic Association II. Acetonitrile-Lithium Salt Mixtures: Highly Dissociated Salts. I. Electrochem. Soc. 2012, 159, A1489-A1500. (c) Borodin, O.; Han, S.-D.; Daubert, J. S.; Seo, D. M.; Yun, S.-H.; Henderson, W. A. Electrolyte Solvation and Ionic Association: VI. Acetonitrile-Lithium Salt Mixtures: Highly Associated Salts Revisited. I. Electrochem. Soc. 2015, 162, A501-A510.

(12) Borodin, O. Polarizable Force Field Development and Molecular Dynamics Simulations of Ionic Liquids. I. Phvs. Chem. B 2009, 113, 11463-11478.

(13) Suo, L.; Borodin, O.; Gao, T.; Olguin, M.; Ho, J.; Fan, X.; Luo, C.; Wang, C.; Xu, K., "Water-in-salt" electrolyte enables high voltage aqueous Li-ion chemistries. Science 2015, in press.

(14) Jeong, S.-K.; Inaba, M.; Iriyama, Y.; Abe, T.; Ogumi, Z. Interfacial reactions between graphite electrodes and propylene carbonate-based solutions: Electrolyte-concentration dependence of electrochemical lithium intercalation reaction. I. Power Sources 2008, 175, 540-546.

(15) Yamada, Y.; Furukawa, K.; Sodeyama, K.; Kikuchi, K.; Yaegashi, M.; Tateyama, Y.; Yamada, A. Unusual Stability of Acetonitrile-Based Superconcentrated Electrolytes for Fast-Charging Lithium-Ion Batteries. I. Am. Chem. Soc. 2014, 136, 5039-5046.

(16) Nie, M.; Abraham, D. P.; Seo, D. M.; Chen, Y.; Bose, A.; Lucht, B. L. Role of Solution Structure in Solid Electrolyte Interphase 
Formation on Graphite with LiPF6 in Propylene Carbonate. I. Phvs. Chem. C 2013, 117, 25381-25389.

(17) Reed, C. A. Carboranes: A new class of weakly coordinating anions for strong electrophiles, oxidants, and superacids. Acc. Chem. Res. 1998, 31, 133-139.

(18) $\mathrm{Xu}, \mathrm{K}$. Nonaqueous Liquid Electrolytes for Lithium-Based Rechargeable Batteries. Chem. Rev. 2004, 104, 4303-4418.

(19) $\mathrm{Xu}, \mathrm{K} . ;$ von Cresce, A. Interfacing electrolytes with electrodes in $\mathrm{Li}$ ion batteries. I. Mater. Chem. 2011, 21, 9849-9864.

(20) Schroder, K. W.; Dylla, A. G.; Bishop, L. D. C.; Kamilar, E. R; Saunders, J.; Webb, L. J.; Stevenson, K. J. Effects of Solute-Solvent Hydrogen Bonding on Nonaqueous Electrolyte Structure. I.Phys. Chem. Lett. 2015, 6, 2888-2891.

(21) Chaban, V. Solvation of the fluorine containing anions and their lithium salts in propylene carbonate and dimethoxyethane. I. Mol. Model. 2015, 21, 1-8.

(22) Bogle, X.; Vazquez, R.; Greenbaum, S.; Cresce, A. v. W.; Xu, K. Understanding $\mathrm{Li}+-$ Solvent Interaction in Nonaqueous Carbonate Electrolytes with $17 \mathrm{O}$ NMR. I. Phvs. Chem. Lett. 2013, 4, 1664-1668.

(23) Borodin, O.; Behl, W.; Jow, T. R. Oxidative Stability and Initial Decomposition Reactions of Carbonate, Sulfone, and Alkyl PhosphateBased Electrolytes. I. Phys. Chem. C 2013, 117, 8661-8682.

(24) Xu, K.; von Wald Cresce, A. Lit-solvation/desolvation dictates interphasial processes on graphitic anode in $\mathrm{Li}$ ion cells. I. Mater. Res. 2012, 27, 2327-2341.

(25) Schroder, K. W.; Dylla, A. G.; Bishop, L. D. C.; Kamilar, E. R; Saunders, J.; Webb, L. J.; Stevenson, K. J. Effects of Solute-Solvent Hydrogen Bonding on Nonaqueous Electrolyte Structure. L.Phvs. Chem. Lett. 2015, 6, 2888-2891.

(26) Seo, D. M.; Borodin, O.; Han, S.-D.; Ly, Q.; Boyle, P. D.; Henderson, W. A. Electrolyte Solvation and Ionic Association. I. Acetonitrile-Lithium Salt Mixtures: Intermediate and Highly Associated Salts. I. Electrochem. Soc. 2012, 159, A553-A565.

(27) Ding, M. S.; Xu, K.; Zhang, S. S.; Amine, K.; Henriksen, G. L.; Jow, T. R. Change of conductivity with salt content, solvent composition, and temperature for electrolytes of LiPF6 in ethylene carbonate-ethyl methyl carbonate. I. Electrochem. Soc. 2001, 148, A1196-A1204.

(28) Ong, M. T.; Verners, O.; Draeger, E. W.; van Duin, A. C. T.; Lordi, V.; Pask, J. E. Lithium Ion Solvation and Diffusion in Bulk Organic Electrolytes from First-Principles and Classical Reactive Molecular Dynamics. I. Phys. Chem. B 2015, 119, 1535-1545.

(29) (a) Plakhotnyk, V. N.; Schmutzler, R.; Ernst, L.; Kovtun, Y. V.; Plakhotnyk, A. V. Influence of the nature of the solvent on the $19 \mathrm{~F}$ chemical shift of the [BF4]- anion. I. Fluorine Chem. 2002, 116, 4144. (b) Plakhotnik, A. V.; Schmutzler, R.; Ernst, L.; Kokunov, Y. V. Ligand Substitution and Interparticle Interactions in Solutions of Fluoroborate Complexes. Russ. I. Coord. Chem. 2004, 30, 224-226.

(30) Xie, B.; Lee, H. S.; Li, H.; Yang, X. Q.; McBreen, J.; Chen, L. Q. New electrolytes using $\mathrm{Li}_{2} \mathrm{O}$ or $\mathrm{Li}_{2} \mathrm{O}_{2}$ oxides and tris(pentafluorophenyl) borane as boron based anion receptor for lithium batteries. Electrochem. Commun. 2008, 10, 1195-1197.

(31) (a) Zhang, S. S.; Xu, K.; Jow, T. R. A thermal stabilizer for LiPF6-based electrolytes of Li-ion cells. Electrochem. Solid-State Lett. 2002, 5, A206-A208. (b) Chen, Z.; Amine, K. Tris(pentafluorophenyl) Borane as an Additive to Improve the Power Capabilities of Lithium-Ion Batteries. I. Electrochem. Soc. 2006, 153, A1221-A1225.

(32) Lee, Y. M.; Lee, Y.-G.; Kang, Y.-M.; Cho, K. Y. Nature of Tris(pentafluorophenyl)borane as a Functional Additive and Its Contribution to High Rate Performance in Lithium-Ion Secondary Battery. Electrochem. Solid-State Lett. 2010, 13, A55-A58.

(33) Sloop, S. E.; Pugh, J. K.; Wang, S.; Kerr, J. B.; Kinoshita, K. Chemical Reactivity of $\mathrm{PF}_{5}$ and $\mathrm{LiPF}_{6}$ in Ethylene Carbonate/ Dimethyl Carbonate Solutions. Electrochem. Solid-State Lett. 2001, 4, A42-A44.

(34) (a) Afroz, T.; Seo, D. M.; Han, S.-D.; Boyle, P. D.; Henderson, W. A. Structural Interactions within Lithium Salt Solvates: Acyclic Carbonates and Esters. I. Phvs. Chem. C 2015, 119, 7022-7027. (b) Seo, D. M.; Afroz, T.; Allen, J. L.; Boyle, P. D.; Trulove, P. C.; De Long, H. C.; Henderson, W. A. Structural Interactions within Lithium Salt Solvates: Cyclic Carbonates and Esters. I. Phvs. Chem. C 2014, $118,25884-25889$.

(35) Xu, K.; Ding, S. P.; Jow, T. R. Toward reliable values of electrochemical stability limits for electrolytes. I. Electrochem. Soc. 1999, 146, 4172-4178.

(36) Tan, S.; Zhang, Z.; Li, Y.; Li, Y.; Zheng, J.; Zhou, Z.; Yang, Y. Tris(hexafluoro-iso-propyl)phosphate as an SEI-Forming Additive on Improving the Electrochemical Performance of the Li[Li0.2Mn0.56Ni0.16Co0.08] O2 Cathode Material. I. Electrochem. Soc. 2013, 160, A285-A292.

(37) Read, J. A.; Cresce, A. V.; Ervin, M. H.; Xu, K. Dual-graphite chemistry enabled by a high voltage electrolyte. Energy Environ. Sci. 2014, 7, 617.

(38) Egashira, M.; Takahashi, H.; Okada, S.; Yamaki, J. Measurement of the electrochemical oxidation of organic electrolytes used in lithium batteries by microelectrode. I. Power Sources 2001, 92, 267-271.

(39) Borodin, O.; Jow, T. R. Quantum Chemistry Studies of the Oxidative Stability of Carbonate, Sulfone and Sulfonate-Based Electrolytes Doped with $\mathrm{BF}_{4}^{-}, \mathrm{PF}_{6}^{-}$Anions. ECS Trans. 2010, 33, $77-84$. 